\title{
Potential seed dispersal distances of native and non-native fleshy fruiting shrubs in the South African Mediterranean climate region
}

\author{
Thabiso Michael Mokotjomela • \\ Charles F. Musil • Karen J. Esler
}

Received: 1 March 2013/Accepted: 4 July 2013/Published online: 13 July 2013

(C) Springer Science+Business Media Dordrecht 2013

\begin{abstract}
Bird flight distances for the small Zosterops capensis, the medium-size Pycnonotus capensis and the large Colius striatus were extracted from these birds' initial ring and subsequent recapture locations and expressed on equivalent per $\mathrm{km}$ bases. The products of the bird-ring recapture records in nine different flight distance categories and daily consumption rates by these birds of seeds of two native (Chrysanthemoides monilifera and Olea europaea spp. africana) and two alien (Lantana camara and Solanum mauritianum) shrubs were used to construct seed dispersal curves. The dispersal distances to which ingested seeds were theoretically restricted were computed from the product of the retention time of seed in the birds' guts and their flight speeds using published functions. All three bird species displayed thin long-tailed seed dispersal curves characterized by peaks at distances below $1 \mathrm{~km}$ which declined progressively with increasing distances, the tails extending to distances of up to $400 \mathrm{~km}$. Flight distances corresponding with predicted seed gut retention times were $9.4 \mathrm{~km}$ in the small Z. capensis,
\end{abstract}

T. M. Mokotjomela $(\varangle) \cdot$ C. F. Musil

Climate Change and Bio-Adaptation Division,

Private Bag X7, Claremont 7735, South Africa

e-mail: t.mokotjomela@sanbi.org.za

T. M. Mokotjomela · K. J. Esler

Department of Conservation Ecology and Entomology

\& Centre for Invasion Biology, Stellenbosch University,

Private Bag X1, Matieland 7602, South Africa
$17.8 \mathrm{~km}$ in the medium size $P$. capensis and $21.2 \mathrm{~km}$ in the large $C$. striatus. These potential seed dispersal distances were much greater that the frequently reported long distance seed dispersal threshold of $1 \mathrm{~km}$ by frugivorous birds in fragmented landscapes.

Keywords Frugivorous birds $\cdot$ Seed dispersal distance $\cdot$ Alien shrubs $\cdot$ Competition $\cdot$ Fleshy fruits

\section{Introduction}

The dispersal of seeds ingested by frugivorous birds over long distances from maternal plants (Van Der Pijl 1982; Higgins et al. 2003; Schurr et al. 2009; Whelan et al. 2008) provide essential genetic links between disconnected plant communities (Nathan et al. 2008; Schupp et al. 2010) by facilitating the formation of new self-sustaining populations in different landscapes (Sakai et al. 2001; Schurr et al. 2007; Nathan et al. 2008; Tsoar et al. 2011). For these reasons, knowledge of bird-mediated seed dispersal is important for predicting future plant distribution ranges (Sakai et al. 2001; Nathan et al. 2008; Tsoar et al. 2011) and in screening potential invasiveness of alien plants in novel environments (Tucker and Richardson 1995; Pheloung et al. 1999; Nel et al. 2004). This is especially pertinent in the South African Mediterranean climate region where alien plants constitute a major threat to the native plant communities (RouraPascual et al. 2009), and heavy habitat fragmentation 
renders the region more vulnerable to extinctions associated with long distance dispersal limitations under global climate change (Schurr et al. 2007; Lenz et al. 2010).

Plant fruit, bird and habitat attributes interact to provide resultant dispersal distance patterns and effectiveness (Gosper and Vivian-Smith 2010; Wotton and Kelly 2012). Different models have been applied to predict seed dispersal distances (Higgins et al. 2003), though all are constrained by inconsistent bird movements (Russo et al. 2006; Gomes et al. 2008), differential gut retention times of seeds by captive and free roaming birds (Levey and Martinez del Rio 2001; Kays et al. 2011; Tsoar et al. 2011) and by birds of different body mass (Schurr et al. 2009; Tsoar et al. 2011). Gut retention time of seeds is influenced by seed size with large seeds consumed by bigger birds generally expelled more rapidly than small seeds (Whittaker and Jones 1994; Levey and Martinez del Rio 2001; Charalambidou et al. 2003; Nathan 2007). Moreover, fruit components such as high concentrations of sucrose and glycoalkaloids have a laxative effect on several monophyletic bird lineages, including starlings, mimids and thrushes which consequently cause seeds to be expelled more rapidly (Murray et al. 1994; Malcarney et al. 1994; Cipollini and Levey 1997). Nevertheless, fruits with high monosaccharide content and small seeds are generally preferred by birds and their seeds are more likely to be dispersed than those of contrasting fruit types (Jordano 2000, Gosper et al. 2005; Gosper and Vivian-Smith 2010; Schupp et al. 2010; Aslan and Rejmanek 2012), such as those with a high lipid content which are difficult to process in bird guts (Fuentes 1994).

There are limited data on how far seeds are dispersed by birds (Nathan 2001) and consequent effects on the recruitment of different plant communities (Wang and Smith 2002; Hyatt et al. 2003; Godinez-Alvarez and Jordano 2007). This is attributed to inconsistent bird flight patterns, imprecise technologies for tracking bird movements (Nathan 2001; Schupp et al. 2002; Russo et al. 2006) and altered seed dispersal patterns induced by defaunation and habitat fragmentation (Herrera 1995; Muller-Landau and Hardesty 2005). It has been reported that habitat fragmentation promotes long distance dispersal by frugivorous birds in Manaus, Brazil, with long distance dispersal probabilities however decreasing with diminished size of habitat fragments, reduced density of fruiting plants and avian dispersers (Uriarte et al. 2011).

Many past field studies have reported relatively short seed dispersal distances by birds of less than $1 \mathrm{~km}$ (Wenny and Levey 1998; Wenny 2000; Levin et al. 2003; Jordano et al. 2007), though longer seed dispersal distances by birds have more recently been reported. Examples include Onychognathus tristramii (Tristram grackle) with an observed foraging range of 14.2-28.3 km in the Negev desert of Israel (Spiegel and Nathan 2007), the dispersal of Virola nobilis seeds over average distances of $1.8 \mathrm{~km}$ per day by wild Ramphastos toucans in the Soberania National Park in Panama (Kays et al. 2011) and reported flight distances of up to $14.5 \mathrm{~km}$ by Ceratogymna hornbills in West Africa (Holbrook and Smith 2000; Holbrook 2011) and trumpeter hornbills Bicanistes bucinator in eastern South Africa forests during their foraging bouts (Lenz et al. 2010).

Both bird flight speeds and retention times of seeds in bird guts have been applied to estimate potential seed dispersal distances. An example is the application of measured gut retention times and flight speeds of the fruit pigeon Ducula pacifica to compute potential distances that Myristica hypagyria seeds are dispersed in Tonga in Western Polynesia (McConkey et al. 2004). Schurr et al. (2009) in an analysis of published records found a high correlation between bird body mass, flight speed, seed load and seed passage time through the gut. Large birds retained seeds for longer periods in their guts and flew longer distances than small birds (Jordano et al. 2007; Tsoar et al. 2011). However, small frugivorous birds do also tend to cover large distances when avoiding dangerous events such as fires (Wilms and Kappelle 2006; Gomes et al. 2008) and when tracking fruit resources (Berthold 1999; Saracco et al. 2004; Telleria et al. 2008). A typical example is that of the tiny (13-26 g) territorial European robin (Erithacus rubecula), which tracks spatially variable fruit over extensive distances in the Spanish Mediterranean scrubland (Telleria et al. 2008). Indeed, such small birds with occasionally extended gut retention times of ingested seeds (Shilton et al. 1999; Spiegel and Nathan 2007) may emulate seed distance dispersal potentials of large birds. In view of these anomalies, we examined how far seeds of fleshy-fruited native and alien shrubs are potentially dispersed by different size bird species in the South Africa Mediterranean climate region. Our hypothesis 
was that seeds of both native and alien shrubs are potentially dispersed by frugivorous birds over much greater distances than the frequently reported long distance seed dispersal threshold of $1 \mathrm{~km}$ in fragmented landscapes.

\section{Methods and materials}

Seed dispersal potential

We used spatial distributions for bird-ring recapture frequency as a proxy of foraging movement behaviour (Cain et al. 2000; Tsoar et al. 2011), and a theoretical vector-based model, based on published allometric equations (Schurr et al. 2009; Tsoar et al. 2011), to establish seed dispersal distances by local bird species. Frequency of bird-ring recapture records provided spatial patterns of bird flight distances (Nathan and Muller-Landau 2000; Nathan et al. 2003). These records were extracted from the South African Bird Atlas Project (SABAP 1 \& 2) databases (Animal Demography Unit, University of Cape Town) for three different size frugivorous bird species, namely the small Zosterops capensis (Cape white-eye), the medium size Pycnonotus capensis (Cape bulbul) and the large Colius striatus (Speckled mousebird) with different gape dimensions (Ally 2010; Chama 2012). These frugivorous bird species were representative in terms of their size, abundance and contribution to seed dispersal in the study region (Knight 1988; Cowling et al. 1997; Hockey et al. 2005; Mokotjomela et al. 2013b). From the bird-ring recapture records, flight distances were derived from the initial ring location and subsequent recapture locations, these calculated geo-spherically with flight distance measures based on the earth's contour rather than on direct vectors. The total numbers of bird-ring recapture records were extracted for nine different flight distance categories, namely $0-1 \mathrm{~km}, \quad 1-2.5 \mathrm{~km}, 2.5-5 \mathrm{~km}, \quad 5-10 \mathrm{~km}$, 10-50 km, 50-100 km, 100-200 km, 200-300 km, $300-400 \mathrm{~km}$. They were expressed on equivalent per $\mathrm{km}$ bases by dividing the numbers of bird-ring recapture records in each category by the distance. The product of the recorded numbers of bird-ring recaptures per $\mathrm{km}$ in each flight distance category and previously published records of the average numbers of seeds of two common native (Chrysanthemoides monilifera and Olea europaea spp. africana) and two common alien (Lantana camara and Solanum mauritianum) shrubs consumed per day by the three different size bird species (Mokotjomela et al. 2013a) were used to construct seed dispersal distance curves as suggested by Cain et al. (2000). The distances on the constructed seed dispersal curves to which seeds were theoretically restricted due to their retention time in bird guts were estimated from the product of the predicted retention time of seed in the birds' guts and their displacement velocities (flight speeds) which have both been expressed as functions of bird body mass (Schurr et al. 2009; Tsoar et al. 2011) as follows:

$\mathrm{GRT}=1.6\{\mathrm{BM}\}^{0.33}$

where GRT is mean gut retention time in hours for ingested seed (h), BM is body mass $(\mathrm{kg})$ and 1.6 and 0.33 are allometric constants

$\mathrm{FS}=15.7\{\mathrm{BM}\}^{0.17}$

where FS is flight speed $\left(\mathrm{m} \mathrm{s}^{-1}\right), \mathrm{BM}$ is body mass $(\mathrm{kg})$ and 15.7 and 0.17 are allometric constants.

\section{Statistical analyses}

A non-parametric Kruskal-Wallis $H$ test tested for differences in the computed numbers of seeds of the four shrub species dispersed per $\mathrm{km}$ by the three different size frugivorous bird species at a flight distances of one $\mathrm{km}$ which is generally presumed the threshold for long distance dispersal in fragmented habitats (Schurr et al. 2009). Significantly different ranked means at $P \leq 0.05$ were separated with a Dunnett multiple comparisons test using mean ranks (UNISTAT ver. 6.0). Differences between shrub species in the numbers of their seeds dispersed per $\mathrm{km}$ were compared with their previously published fruit and seed attributes (Mokotjomela et al. 2013a).

\section{Results}

Seed dispersal potential

All three bird species displayed typical thin long-tailed flight distance curves characterized by peaks at flight distances below $1 \mathrm{~km}$ which declined progressively with increasing bird flight distances with tails extending to distances of up to $400 \mathrm{~km}$ in Z. capensis and C. striatus and $200 \mathrm{~km}$ in P. capensis (Figs. 1a, 2a, 3a). 
P. capensis also displayed a secondary dispersal peak evident at a flight distance of between 2.5 and $5 \mathrm{~km}$. However, computed flight distances corresponding with seed gut retention times did in all three bird species exceed the distances corresponding with their primary dispersal peaks (Figs. 1a, 2a, 3a) and in $P$. capensis even the distance corresponding with its secondary dispersal peak (Fig. 2a).

At flight distances between 0 and $1 \mathrm{~km}$, all three bird species dispersed significantly $(P \leq 0.001)$ greater numbers of seeds of the alien $S$. mauritianum than seeds of the alien $L$. camara and the two native shrubs $O$. africana and $C$. monilifera (Table 1). Up to 10,23 and 35 times greater numbers of $S$. mauritianum seeds were dispersed by the small $Z$. capensis, the medium-size $P$. capensis and the large $C$. striatus respectively than seeds of the other three shrub species. In fact, consistently greater numbers of S. mauritianum seeds were dispersed at all flight distances (Figs 1b, 2b, 3b), this was corresponding
Fig. 1 a Numbers of birdring recapture records per $\mathrm{km}$ in different flight distance categories for the small Z. capensis (Cape white-eye) and $\mathbf{b}$ numbers of seeds per $\mathrm{km}\left(\log _{\mathrm{e}}\right)$ of two native shrubs (C. monilifera, $O$. africana) and two alien shrubs (L. camara, $S$. mauritianum) dispersed by Z. capensis with increasing flight distances. Seed dispersal distance is the product of the predicted gut retention time and flight speed (a)

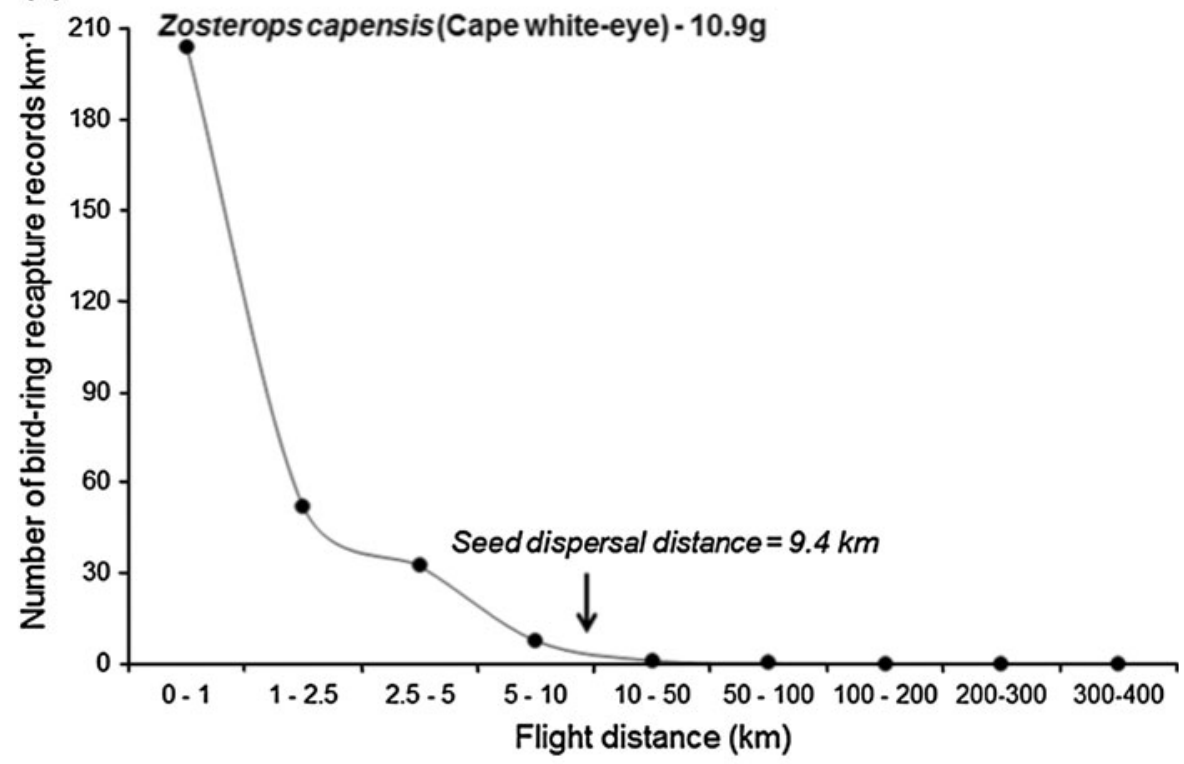

(b)

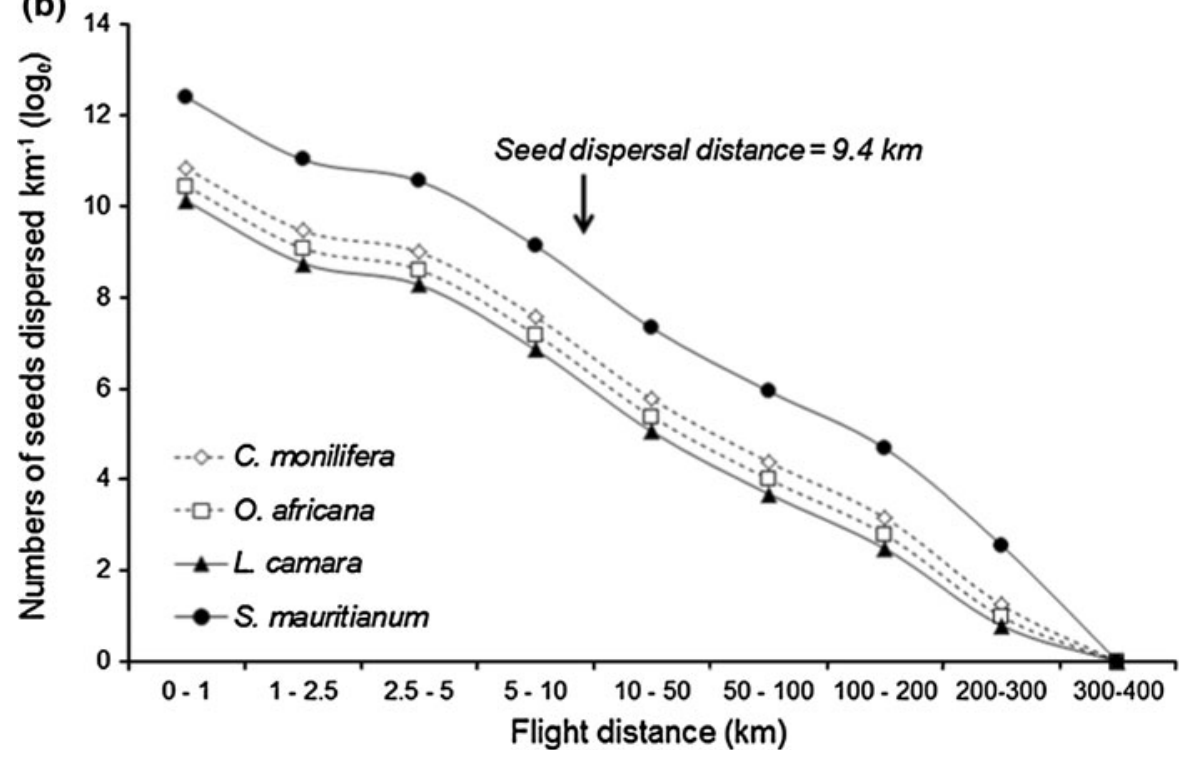


Fig. 2 a Numbers of birdring recapture records per $\mathrm{km}$ in different flight distance categories for the medium size $P$. capensis (Cape bulbul) and b numbers of seeds per $\mathrm{km}$ $\left(\log _{\mathrm{e}}\right)$ of two native shrubs (C. monilifera, O. africana) and two alien shrubs (L. camara, S. mauritianum) dispersed by $P$. capensis with increasing flight distances. Seed dispersal distance is the product of the predicted gut retention time and flight speed


with $S$. mauritianum's significantly $(P \leq 0.001)$ greater fruit mass and energy (monosaccharide) content and seed numbers per $\mathrm{m}^{2}$ canopy area than that of the other alien and native shrub species (Table 1).

The medium-size $P$. capensis also consumed and dispersed significantly $(P \leq 0.001)$ greater numbers of seeds of the alien shrub $L$. camara than seeds of the native shrub $C$. monilifera but not seeds of the native shrub $O$. africana at flight distances between 0 and $1 \mathrm{~km}$ (Table 1). In contrast, the large $C$. striatus consumed and dispersed significantly $(P \leq 0.001)$ greater numbers of seeds of the native $C$. monilifera than seeds of the native $O$. africana and seeds of the alien shrub $L$. camara at flight distances between 0 and $1 \mathrm{~km}$ (Table 1).

\section{Discussion}

Results conformed to the study hypothesis in that all three bird species displayed potential seed dispersal distances much greater than the frequently reported long distance seed dispersal threshold of $1 \mathrm{~km}$ by 
Fig. 3 a Numbers of birdring recapture records per $\mathrm{km}$ in different flight distance categories for the large C. striatus (speckled mousebird) and $\mathbf{b}$ numbers of seeds per $\mathrm{km}\left(\log _{\mathrm{e}}\right)$ of two native shrubs (C. monilifera, O. africana) and two alien shrubs (L. camara, $S$. mauritianum) dispersed by C. striatus with increasing flight distances. Seed dispersal distance is the product of the predicted gut retention time and flight speed

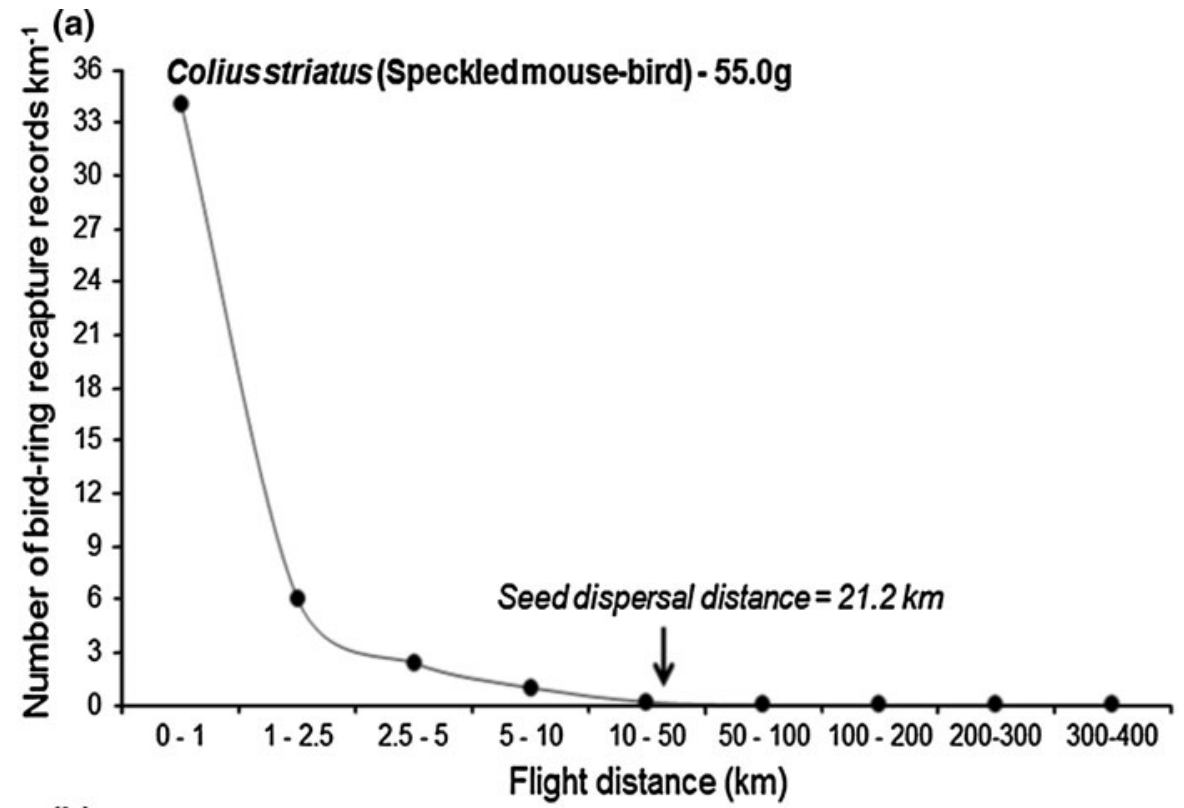

(b)

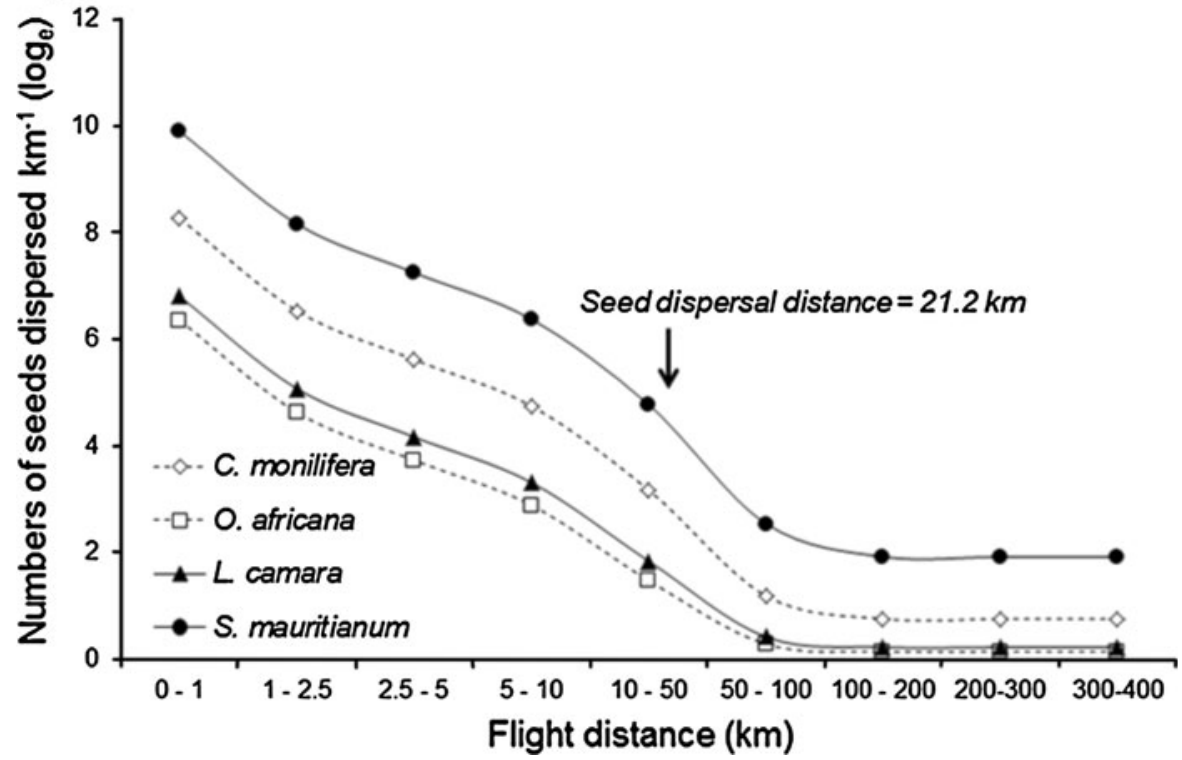

frugivorous birds in fragmented landscapes. Potential seed dispersal distances ranged from $9.4 \mathrm{~km}$ in the small Z. capensis, $17.8 \mathrm{~km}$ in the medium size $P$. capensis, to $21.2 \mathrm{~km}$ in the large $C$. striatus. With the exception of the seed dispersal distance of up to $12 \mathrm{~km}$ reported for Zosterops lateralis (silvereye) in south-western Australia (Stansbury 2001), the seed dispersal distances computed for the different size bird species in this study were all substantially longer than seed dispersal distances of less than $1 \mathrm{~km}$ reported for small and medium size passerine birds in Costa Rica (Wenny 2000) and in Spain (Jordano et al. 2007) and the frequently observed long distance dispersal threshold of $1 \mathrm{~km}$ for frugivorous birds in fragmented landscapes (Nathan et al. 2003; Schurr et al. 2009). Indeed, recent studies by Lenz et al. (2010) and Kays et al. (2011) have concluded from GPS tracking of birds in South Africa and Panama that long distance dispersal by flying vertebrates is more common than previously envisaged (Tsoar et al. 2011). 


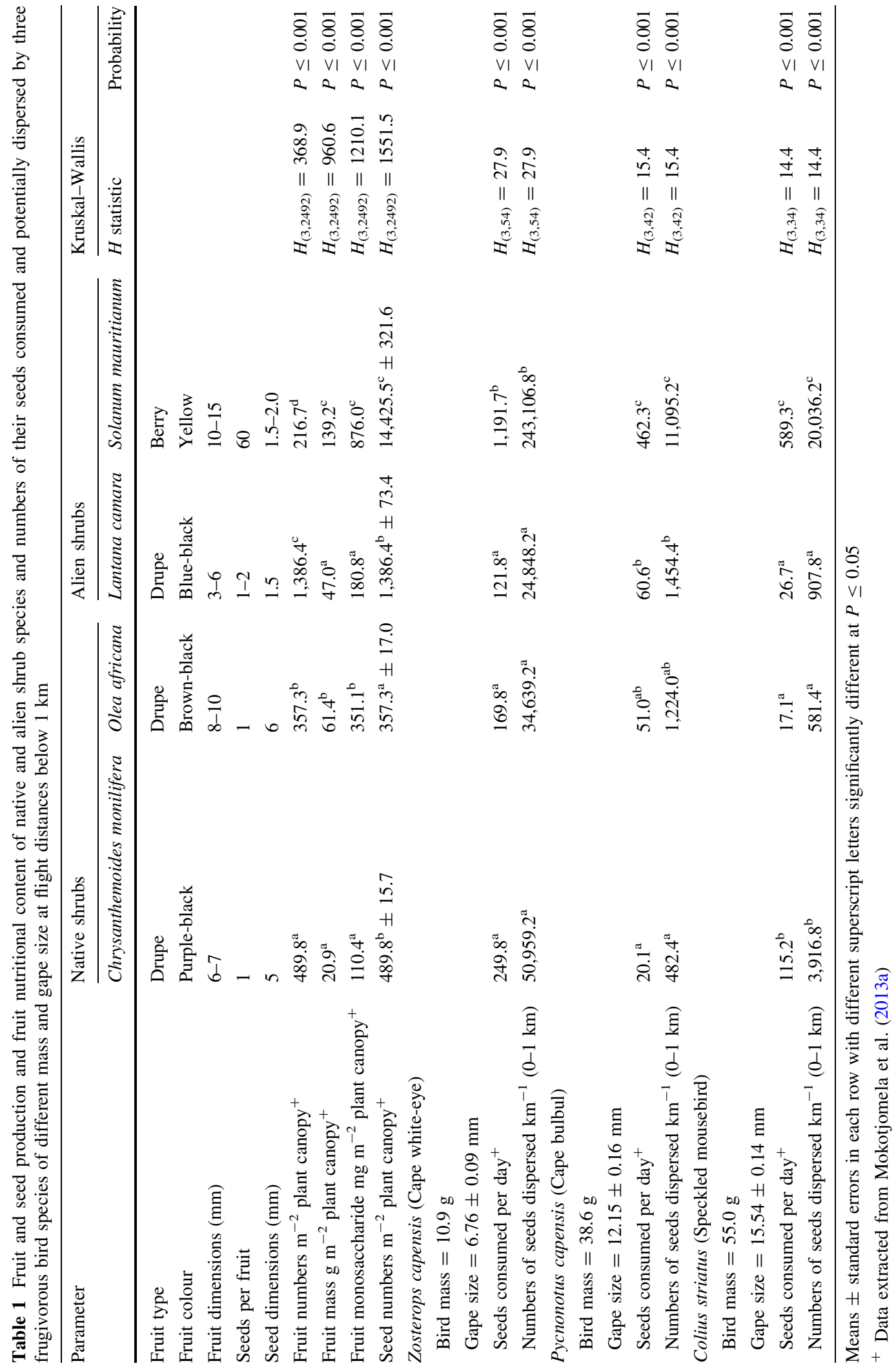


In addition, fruit resource tracking by frugivorous birds in highly fragmented natural habitats may also explain dispersal of seed to distances longer than anticipated $1 \mathrm{~km}$ thresholds. Fruit tracking has been observed in the territorial E. rubecula (European robin) in the Spanish Mediterranean scrubland (Telleria et al. 2008), in flocks of wintering frugivorous thrushes Turdus torquatus and T. viscivorus in southeastern Spain, which fly between isolated fruiting populations of the Juniperus communis (Garcia and Ortiz-Pulido 2004) as well as in T. albicollis (whitethroated thrush) which disperse seeds over longer distances in fragmented habitats in Brazil (Uriarte et al. 2011). Although Perez-Tris and Telleria (2002) reported that only wintering migrant bird species display extensive spatial fruit tracking movements in Spanish shrublands, altitudinal migrations of sedentary bird species driven by resource dynamics are also known (Johnson 1992; Berthold 1999). However, the distribution of bird ring-recapture records in our study with long tails extending up to $400 \mathrm{~km}$ do imply that some sedentary bird species may also track fruits beyond their daily range. Furthermore, bird flights to distant patches to avoid fires which occasionally occur in the natural vegetation of the South African Mediterranean climate region (Cowling et al. 1989) may also facilitate long distant seed dispersal.

The thin long-tailed dispersal curves displayed by all three bird species in this study, which extended to distances of up to $400 \mathrm{~km}$ were indicative of a high potential for long distance dispersal (Portnoy and Willson 1993; Gomez and Espadaler 1998; Nathan et al. 2008). This is because the seed retention time by a dispersal vector or the vector displacement velocity or both may be occasionally high and consequently contribute prolonged transport of even small seed loads (Nathan et al. 2008). Such long-tailed dispersal curves are important for maintenance of metapopulations (Cain et al. 2000; Nathan et al. 2008), since they allow for a high diversity of movement of seeds from distant plant communities (Gomez and Espadaler 1998; Klein et al. 2006). They have been implicated in large-scale changes in natural plant communities, plant range shifts following climate change and persistence of species in fragmented landscapes (Levin et al. 2003; Schurr et al. 2007; Nathan et al. 2008; Lenz et al. 2010) and consequently may likely explain the rapid spread of fleshy fruited invasive alien plants in the South African Mediterranean climate region.
Noteworthy also in this study's findings was that greater quantities of $S$. mauritianum than L. camara, $C$. monilifera and $O$. africana seeds were consumed and dispersed by all three different size frugivorous bird species. S. mauritianum possessed the largest most conspicuous, abundant and nutritious fruits which concurred with foraging theory that proposes that fruit size plays an important role in fruit conspicuousness and thus selection by birds (Johnson et al. 1985; Sallabanks 1993; Carlo and Morales 2008). Indeed, Knight (1988) found that fruit consumption by birds in the south-western Cape, South Africa was mostly dependent on abundance and availability. Also, fruit pulp mass has been reported as the principal determinant of fruit choice by T. migratorius (American robins) in western Oregon of the USA (Sallabanks 1993) and fruit abundance the best predictor of fruit removal by birds from Phillyrea latifolia trees growing in Spanish scrublands (Herrera et al. 1994). Similarly, large berries such as those of $S$. maritianum are often preferred by birds over other fruit types in southern Africa (Knight and Siegfried 1983) as they produce copious amounts of small seeds which increases their probability of removal and dispersal by birds (Murray 1987; Knight 1988; Herrera et al. 1994). In this regard, Gosper and Vivian-Smith (2010) demonstrated that invasive alien plants dispersed by birds in Australia possess small numerous fruits/seeds and nutritious pulp. Small seeds are ingested in large numbers and retained for prolonged periods in the gut of birds (Levey and Martinez del Rio 2001; Spiegel and Nathan 2007), which might account for the relatively higher dispersal potential of seeds of S. mauritianum than other shrub species in this study.

Aslan and Rejmanek (2010) proposed that native fruiting shrubs can compete as effectively for seed dispersal agents if they possess similar visual and nutritional fruit attributes as those of alien species. This proposal was partly supported by this study's finding as seeds from the purple-black, brown-black and blueblack fruits of C. monilifera, O. africana and L. camara respectively were consumed and dispersed in insignificantly different quantities by the small $Z$. capensis. Indeed, the predominance of red and black fleshy fruits in the wild and trends in frugivorous feeding habits (Knight 1988; Fischer and Chapman 1993) tend to support the proposition that these fruit colours are more preferential than other colours to foraging birds (Knight and Siegfried 1983; Willson and Whelan 
1990; Burns 2005). However, our findings partly contrasted this proposition as the yellowish fruits of S. mauritianum were consumed in significantly greater quantities by all three bird species than the fruits of C. monilifera, O. africana and L. camara respectively. In this regard, Ally (2010) also found that $C$. striatus given equal access to six different colours of artificial fruits of equal nutritional value displayed no significant preference for black and/or red fruits, though green fruits were eaten less frequently than preferred orange and yellow coloured fruits. Consistently, the large yellow coloured fruits of $S$. mauritianum likely augmented their conspicuousness and detection by avian frugivores, since fruit encounter rates are related to fruit detection ability (Knight and Siegfried 1983; Cazetta et al. 2009) which is partly enhanced by fruit colours (Willson and Whelan 1990; Burns et al. 2009). Brightly coloured fruits increase detectability by their colour contrast/conspicuousness against background (Knight and Siegfried 1983; Willson and Whelan 1990; Burns 2005; Cazetta et al. 2009).

Acknowledgments Funds for this project were provided by the Andrew Mellon Foundation, the Oppenheimer Memorial Trust and Lesotho Government which were administered by the South African National Biodiversity Institute and Stellenbosch University both of which also provided research facilities. The Avian Demography Unit, University of Cape Town provided important bird-ringing and recapture data (Prof. Less Underhill and Mr. Mike Brooks). Mr. Stanley Snyders provided technical assistance in the field. Mr. Leslie Powrie helped extracting records of plant distribution from databases.

\section{References}

Ally E (2010) Avian fruit selection and sugar preferences. MSc thesis, University of Kwazulu Natal, South Africa

Aslan C, Rejmanek M (2010) Avian use of introduced plants: ornithologist records illuminate interspecific associations and research needs. Ecol Appl 20:1005-1020

Aslan C, Rejmanek M (2012) Native fruit traits may mediate dispersal competition between native and non-native plants. NeoBiota 12:1-24

Berthold P (1999) Towards a comprehensive theory for the evolution, control and adaptability of avian migration. In: Adams NJ, Slotow RH (eds) Proceedings of 22nd International Ornithological Congress, Durban, Ostrich, vol 70, pp $1-11$

Burns KC (2005) Effects of bi-colored displays on avian fruit color preferences in a color polymorphic plant. J Torrey Bot Soc 132:505-509

Burns KC, Cazetta E, Galetti M, Valido A, Schaefer HM (2009) Geographic patterns in fruit colour diversity: do leaves constrain the colour of fleshy fruits? Oecologia 159:337-343

Cain ML, Milligan BG, Strand AE (2000) Long-distance seed dispersal in plant populations. Am J Bot 87:1217-1227

Carlo TA, Morales JM (2008) Inequalities in fruit-removal and seed dispersal: consequences of bird behaviour, neighbourhood density and landscape aggregation. J Ecol 96:609-618

Cazetta E, Schaefer HM, Galetti M (2009) Why are fruits colorful? The relative importance of achromatic and chromatic contrasts for detection by birds. Evol Ecol 23:233-244

Chama L (2012) Plant-frugivore interactions in a heterogeneous forest landscape of South Africa. PhD thesis, PhilippsUniversity of Marburg, Germany

Charalambidou I, Santamaria L, Langevoord O (2003) Effect of ingestion by five avian dispersers on the retention time, retrieval and germination of Ruppia maritima seeds. Funct Ecol 17:747-753

Cipollini ML, Levey DJ (1997) Secondary metabolites of fleshy vertebrate-dispersed fruits: adaptive hypotheses and implications for seed dispersal. Am Nat 150:46-372

Cowling RM, Kirkwood D, Midgley JJ, Pierce SM (1997) Invasion and persistence of bird-dispersed, subtropical thicket and forest species in fire-prone coastal fynbos. J Veg Sci 8:475-488

Cowling RM, Russel GE, Hoffman MT, Hilton-Taylor C (1989) Patterns of plant species diversity in southern Africa. In: Huntley B (ed) Biotic diversity in southern Africa. Concept and conservation. Oxford University Press, Cape Town, pp 19-50

Fischer KE, Chapman CA (1993) Frugivores and fruit syndromes: differences in patterns at the genus and species level. Oikos 66:472-482

Fuentes M (1994) Diets of fruit-eating birds: what are the causes of interspecific differences? Oecologia 97:134-142

Garcia D, Ortiz-Pulido R (2004) Patterns of resource tracking by avian frugivores at multiple spatial scales: two case studies on discordance among scales. Ecography 27:187-196

Godinez-Alvarez H, Jordano P (2007) An empirical approach to analysing the demographic consequences of seed dispersal by frugivores. In: Dennis AJ, Schupp EW, Green RJ, Westcott D (eds) Seed dispersal: theory and its application in a changing world. Biddles Ltd., Reading, pp 391-406

Gomes LGL, Oostra V, Nijman V, Cleef AM, Kappelle M (2008) Tolerance of frugivorous birds to habitat disturbance in a tropical cloud forest. Biol Conserv 14:860-871

Gomez C, Espadaler X (1998) Seed dispersal curve of a Mediterranean myrmecochore: influence of ant size and the distance to nests. Ecol Res 13:354-374

Gosper CR, Vivian-Smith G (2010) Fruit traits of vertebratedispersed alien plants: smaller seeds and more pulp sugar than native species. Biol Invasions 12:2153-2163

Gosper CR, Stansbury CD, Vivian-Smith G (2005) Seed dispersal of fleshy-fruited invasive plants by birds: contributing factors and management options. Divers Distrib 11:549-558

Herrera CM (1995) Plant-vertebrate seed dispersal systems in the Mediterranean: ecological, evolutionary, and historical determinants. Annu Rev Ecol Syst 26:705-727

Herrera CM, Jordano P, Lopez-Soria L, Amat JA (1994) Recruitment of a mast-fruiting, bird-dispersed tree: 
bridging frugivore activity and seedling establishment. Ecol Monogr 64:315-344

Higgins SI, Nathan R, Cain ML (2003) Are long-distance dispersal events in plants usually caused by nonstandard means of dispersal? Ecology 84:1945-1956

Hockey PAR, Dean WRJ, Ryan PG (eds) (2005) Roberts' birds of Southern Africa, 7th edn. John Voelcker Bird Book Fund, Cape Town

Holbrook KM (2011) Home range and movement patterns of Toucans: implications for seed dispersal. Biotropica 43:357-364

Holbrook KM, Smith TB (2000) Seed dispersal and movement patterns in two species of Ceratogymna hornbills in a West African tropical lowland forest. Oecologia 125:249-257

Hyatt L, Rosenberg MS, Howard TG, Bole G, Fang W, Anastasia J, Brown K, Grella R, Hinman K, Kurdziel JP, Gurevitch $J$ (2003) The distance dependence prediction of the Janzen-Connell hypothesis: a meta-analysis. Oikos 103:590-602

Johnson SD (1992) Plant-animal relationships. In: Cowling RM (ed) The ecology of fynbos: nutrients, fire and diversity. Oxford University Press, Cape Town, pp 175-205

Johnson RA, Willson MF, Thompson JN, Bertin RI (1985) Nutritional values of wild fruits and consumption by migrant frugivorous birds. Ecology 66:819-827

Jordano P (2000) Fruits and frugivory. In: Fenner M (ed) Seeds: the ecology of regeneration in natural plant communities. CABI Publishers, Wallingford, UK, pp 125-166

Jordano P, Garcia C, Godoy JA, Garcia-Castano JL (2007) Differential contribution of frugivores to complex seed dispersal patterns. Proc Natl Acad Sci USA 104:3278-3282

Kays R, Jansen PA, Knecht EMH, Vohwinkel R, Wikelski M (2011) The effect of feeding time on dispersal of Virola seeds by toucans determined from GPS tracking and accelerometers. Acta Oecol 37:625-631

Klein ET, Lavigne C, Gouyon H (2006) Mixing of propagules from discrete sources at long distance: comparing a dispersal tail to an exponential. BMC Ecol. doi:10.1186/ 1472-6785-6-3

Knight RS (1988) Aspects of plant dispersal in the south-western Cape with particular reference to the roles of birds as dispersal agents. PhD dissertation, University of Cape Town, South Africa

Knight RS, Siegfried WR (1983) Inter-relationships between type, size and colour of fruits and dispersal in southern African trees. Oecologia 56:405-412

Lenz J, Fiedler W, Caprano T, Friedrichs W, Gaese BH, Wikelski M, Bohning-Gaese K (2010) Seed-dispersal distributions by trumpeter hornbills in fragmented landscapes. Proc R Soc B: Biol Sci. doi:10.1098/rspb.2010.2383

Levey DJ, Martinez del Rio C (2001) It takes guts (and more) to eat fruit: lessons from avian nutritional ecology. Auk 118:819-831

Levin SA, Muller-Landau HC, Nathan R, Chave J (2003) The ecology and evolution of seed dispersal: a theoretical perspective. Annu Rev Ecol Evol Syst 34:575-604

Malcarney HL, Martinez del Rio C, Apanius V (1994) Sucrose intolerance in birds: simple nonlethal diagnostic methods and consequences for assimilation of complex carbohydrates. Auk 111:170-177
McConkey KR, Meehan MH, Drake DR (2004) Seed dispersal pacific pigeon Ducula pacifica in Tonga, western Polynesia. Emus 104:369-376

Mokotjomela TM, Musil CF, Esler KJ (2013a) Do frugivorous birds concentrate their foraging activities on those alien plants with the most abundant and nutritious fruits in the South African Mediterranean-climate region? Plant Ecol 214:49-59

Mokotjomela TM, Musil CF, Esler KJ (2013b) Frugivorous birds visit fruits of emerging alien shrub species more frequently than those of native shrub species in the South African Mediterranean climate region. S Afr J Bot 86:73-78

Muller-Landau HC, Hardesty BD (2005) Seed dispersal of woody plants in tropical forests: concepts, examples, and future directions. In: Burslem D, Pinard M, Hartley S (eds) Biotic interactions in the tropics: their role in the maintenance of species diversity. Cambridge University Press, Cambridge, pp 267-309

Murray KG (1987) Selection for optimal fruit-crop size in birddispersed plants. Am Nat 129:18-31

Murray KG, Russell S, Picone CM, Winnett-Murray K, Sherwood W, Kuhlmann ML (1994) Fruit laxatives and seed passage rates in frugivores: consequences for plant reproductive success. Ecology 75:989-994

Nathan R (2001) The challenges of studying dispersal. Trends Ecol Evol 16:481-483

Nathan R (2007) Total dispersal kernel and the evaluation of diversity and similarity in complex dispersal systems. In: Dennis AJ, Schupp EW, Green RJ, Westcott D (eds) Seed dispersal: theory and its application in a changing world. Biddles Ltd., Reading, pp 252-256

Nathan R, Muller-Landau HC (2000) Spatial patterns of seed dispersal, their determinants and consequences for recruitment. Trends Ecol Evol 15:278-285

Nathan R, Perry G, Cronin JT, Strand AE, Cain ML (2003) Methods for estimating long-distance dispersal. Oikos 103:261-273

Nathan R, Schurr FM, Spiegel O, Steinitz O, Trakhtenbrot A, Tsoar A (2008) Mechanisms of long-distance seed dispersal. Trends Ecol Evol 23:638-647

Nel JL, Richardson DM, Rouget M, Mgidi TN, Mdzeke N, Le Maitre DC, van Wilgen BW, Schonegevel L, Henderson L, Neser S (2004) A proposed classification of invasive alien plant species in South Africa: towards prioritizing species and areas for management action. S Afr J Sci 100:53-64

Perez-Tris J, Telleria JL (2002) Migratory and sedentary blackcaps in sympatric non-breeding grounds: implications for the evolution of avian migration. $\mathrm{J}$ Anim Ecol 71:211-224

Pheloung PC, Williams PA, Halloy SR (1999) A weed risk assessment model for use as a biosecurity tool evaluating plant introductions. J Environ Manag 57:239-251

Portnoy S, Willson MF (1993) Seed dispersal curves: behavior of the tail of the distribution. Evol Ecol 7:25-44

Roura-Pascual N, Richardson DM, Krug RM, Brown A, Chapman AR, Forsyth GG, Le Maitre DC, Robertson MP, Stafford L, Van Wilgen BW, Wannenburgh A, Wessels N (2009) Ecology and management of alien plant invasions in South African fynbos: accommodating key complexities in objective decision making. Biol Conserv 142:1595-1604 
Russo SE, Portnoy S, Augspurger CK (2006) Incorperating animal behaviour into seed dispersal models: implications for seed shadows. Ecology 87:3160-3174

Sakai AK, Weller SG, Allendorf FW, Holt JS, Lodge DM, Molofsky J, With KA, Baughman S, Cabin RJ, Cohen JE, Ellstrand NC, McCauley DE, O'Neil P, Parker IM, Thompson JN (2001) The population biology of invasive species. Annu Rev Ecol Syst 32:305-332

Sallabanks R (1993) Hierarchical mechanisms of fruit selection by an avian frugivore. Ecology 74:1326-1336

Saracco JF, Collazo JM, Groom MJ (2004) How do frugivores track resources? Insights from spatial analyses of bird foraging in a tropical forest. Oecologia 139:235-245

Schupp EW, Milleron T, Russo SE (2002) Dissemination limitation and the origin and maintenance of species-rich tropical forests. In: Levey DJ, Silva WR, Galetti M (eds) Seed dispersal and frugivory: ecology, evolution and conservation. CABI International, Wallingford, pp 19-33

Schupp EW, Jordano P, Gómez JM (2010) Seed dispersal effectiveness revisited: a conceptual review. New Phytol 188:333-353

Schurr FM, Midgley GF, Rebelo AG, Reeves G, Poschlod P, Higgins SI (2007) Colonization and persistence ability explain the extent to which plant species fill their potential range. Glob Ecol Biogeogr 16:449-459

Schurr FM, Spiegel O, Steinitz O, Trakhtenbrot A, Tsoar A, Nathan N (2009) Long-distance seed dispersal. Ann Plant Rev 38:204-237

Shilton LA, Altringham JD, Compton SG, Whittaker RJ (1999) Old world fruit bats can be long-distance seed dispersers through extended retention of viable seeds in the gut. Proc R Soc Lond Ser B: Biol Sci 26:219-223

Spiegel O, Nathan R (2007) Incorporating dispersal distance into the disperser effectiveness framework: frugivorous birds provide complementary dispersal to plants in a patchy environment. Ecol Lett 10:718-728

Stansbury CD (2001) Dispersal of the environmental weed bridal creeper, Asparagus asparagoides, by silvereyes, Zosterops lateralis, in southwestern Australia. Emu 101: $39-45$

Telleria LJ, Ramirez A, Pérez-Tris J (2008) Fruit tracking between sites and years by birds in Mediterranean wintering grounds. Ecography 31:381-388
Tsoar A, Shohami D, Nathan R (2011) A movement ecology approach to study seed dispersal and plant invasion: an overview and application of seed dispersal by fruit bats. In: Richardson DM (ed) Fifty years of invasion ecology. The legacy of Charles Elton. Wiley-Blackwell, Oxford, pp 103-119

Tucker KC, Richardson DM (1995) An expert system for screening potentially invasive alien plants in South African fynbos. J Environ Manag 44:309-338

Uriarte M, Anciaes M, Mariana TB, Silva D, Rubim P, Johnson E, Emilio M, Bruna EM (2011) Disentangling the drivers of reduced long-distance seed dispersal by birds in an experimentally fragmented landscape. Ecology 92:924-937

Van Der Pijl L (1982) Principles of dispersal in higher plants, 3rd edn. Springer, Berlin

Wang BC, Smith TB (2002) Closing the seed dispersal loop. Trends Ecol Evol 17:379-386

Wenny DG (2000) Seed dispersal of a high quality fruit by specialized frugivores: high quality dispersal? Biotropica 32:327-337

Wenny DG, Levey DJ (1998) Directed seed dispersal by bellbirds in a tropical cloud forest. Proc Natl Acad Sci USA 95:6204-6207

Whelan CJ, Wenny DG, Marquis RJ (2008) Ecosystem services provided by birds. Ann N Y Acad Sci 1134:25-60

Whittaker RJ, Jones SH (1994) The role of frugivorous bats and birds in the rebuilding of a tropical forest ecosystem, Krakatau, Indonesia. J Biogeogr 21:245-258

Willson MF, Whelan CJ (1990) The evolution of fruit color in fleshy-fruited plants. Am Nat 136:790-809

Wilms JJAM, Kappelle M (2006) Frugivorous birds and seed dispersal in disturbed and old growth montane oak forests in Costa Rica. In: Kappelle M (ed) Ecology and conservation of neotropical Montane Oak forests. Ecological studies series 185, Springer-Verlag, New York/Berlin/ Heidelberg, pp 309-324

Wotton DM, Kelly D (2012) Do larger frugivores move seeds further? Body size, seed dispersal distance, and a case study of a large, sedentary pigeon. J Biogeogr 39:1973-1983 